\title{
PENGEMBANGAN INDEKS KUALITAS AIR SEBAGAI ALTERNATIF PENILAIAN KUALITAS AIR SUNGAI
}

\section{THE DEVELOPMENT OF WATER QUALITY INDEX AS AN ALTERNATIVE ASSESSMENT OF RIVER WATER QUALITY}

\author{
Dewi Ratnaningsih ${ }^{1}$, Retno Puji ${ }^{1}$ Lestari, Ernawita Nazir ${ }^{1}$, dan Ridwan Fauzi ${ }^{1}$ \\ (Diterima tanggal 12 Juli 2018, Disetujui tanggal 8 September 2018)
}

\begin{abstract}
ABSTRAK
Pengembangan Indeks Kualitas Air (IKA) sebagai hasil modifikasi NSF-WQI merupakan proses lanjutan dari penyusunan IKA yang telah dilakukan pada tahun 2016. Pengembangan IKA dilaksanakan dengan melakukan verifikasi terhadap komponen penyusun IKA yang meliputi kurva sub indeks, pembobotan parameter, dan verifikasi lapangan terhadap hasil formulasi IKA. Verifikasi lapangan dilakukan pada delapan lokasi di Sungai Ciliwung. Verifikasi lapangan menunjukkan bahwa nilai IKA yang diperoleh dari hasil pengujian kualitas air di laboratorium dan hasil verifikasi lapangan oleh panelis menunjukkan nilai yang tidak berbeda nyata $(\mathrm{p}<0,01)$, sehingga rumusan IKA yang telah dikembangkan sesuai digunakan untuk penilaian Sungai Ciliwung. Nilai IKA dikembangkan menjadi enam kriteria yaitu sangat baik $(100 \leq \mathrm{I}>90)$, baik $(90 \leq \mathrm{I} \geq 80)$, cukup baik $(80<\mathrm{I} \geq 70)$, sedang $(70<$ $\mathrm{I} \geq 51)$, marginal $(51<\mathrm{I} \geq 36)$, dan buruk $(36<\mathrm{I} \geq 0)$. Penerapan IKA di lapangan menunjukkan bahwa salah satu sumber mata air Sungai Ciliwung yang berada di wilayah lereng Gunung Pangrango mempunyai nilai 91 dengan kriteria sangat bagus. Sungai Condet sebagai salah satu anak sungai Ciliwung dengan sumber pencemar domestik yang tinggi berada pada nilai 35.5 dengan kriteria buruk. Enam lokasi Sungai Ciliwung lainnya berada pada kriteria marginal sampai baik. Rumusan IKA yang telah diperoleh dapat diaplikasikan untuk instrumen penilaian sungai dan hasilnya dapat dimanfaatkan untuk perencanaan dan evaluasi pengendalian pencemaran air sungai.
\end{abstract}

Kata Kunci: Indek kualitas air (IKA), verifikasi, kurva sub-indeks, parameter, pembobotan, Sungai Ciliwung

\begin{abstract}
Development of Water Quality Index (WQI) as a result of NSF-WQI modification is an advanced design process of WQI that has been carried out in 2016. The progress of IKA was determined through verification of the constituent component of WQI, comprising sub index curve, parameter weighting, and field verification of WQI formulation results. Field verification was conducted at eight locations of the Ciliwung River. The results indicated that the WQI score obtained from the water quality testing result in the laboratory and field verification results by panelists conducted at the same time indicated a value that was not significantly different, so that the WQI formulation has been developed as appropriate for the Ciliwung River assessment. The value of WQI developed into six criteria which is very good $(100 \leq I>90)$, good $(90 \leq I \geq 80)$, good enough $(80<I \geq 70)$, medium $(70<I \geq 51)$, marginal $(5 I<I \geq 36)$, and bad $(36<I \geq 0)$. The result of IKA application shows that one of the Ciliwung River springs located on the slopes of Mount Pangrango has a value of 91 which is within very good criteria. Condet River categorized as one of the Ciliwung creeks with high domestic pollutants, has a value of 35.5 which is display bad criteria. Six other Ciliwung River locations are on marginal to good criteria. WQI formulation that has been obtained can be applied as the instrument of river assessment and the results can be used for planning and evaluation of river water contamination control.
\end{abstract}

Keyword: Water quality index (WQI), verification, sub index curve, parameter, weighting, Ciliwung River

\footnotetext{
${ }^{1}$ Puslitbang-Kualitas dan Laboratorium Lingkungan KLHK. Kawasan Puspiptek gedung 210, J1 Raya Puspiptek-Serpong, Tangerang Selatan, Banten. (dewirinie@yahoo.com)
} 


\section{PENDAHULUAN}

Pertumbuhan industri dan penduduk yang pesat dapat menyebabkan dampak negatif terhadap lingkungan. Air merupakan salah satu sumber daya alam yang akan menerima dampak negatif dari pesatnya pertumbuhan tersebut. Pencemaran air menjadi masalah yang terus berlangsung baik untuk air permukaan yang ada di sungai, danau, maupun lautan. Air dalam tanah juga tidak terlepas dari pencemaran yang terjadi. Manusia dengan berbagai aktivitasnya baik di bidang industri, pertanian, peternakan atau rumah tangga memberikan kontribusi yang besar terhadap pencemaran air [1], [2], [3]. Di sisi lain kualitas air yang baik, bersih dan sehat menjadi kebutuhan penting bagi manusia dan mahkluk hidup yang lain. Penilaian kualitas air menjadi hal yang penting untuk dilakukan agar dapat diketahui apakah air yang ada di suatu wilayah sesuai untuk mendukung kebutuhan hidup manusia dan mahluk hidup yang ada di lokasi tersebut [4].

Berbagai metode tersedia untuk melakukan penilaian kualitas air. Informasi yang diperoleh dari berbagai metode tersebut juga bervariasi. Informasi kualitas air ini penting bagi masyarakat dan pengambil kebijakan, namun pada umumnya informasi kualitas air yang disampaikan masih berdasarkan konsentrasi masing-masing parameter, sehingga susah dipahami makna informasi yang disampaikan. Pengambil kebijakan, manajer non teknis di bidang air atau masyarakat biasanya tidak mempunyai waktu untuk mempelajari dan memahami tinjauan data teknis kualitas air. Pengambil kebijakan dan masyarakat membutuhkan informasi sederhana yang mudah dipahami untuk mengetahui bagaimana kualitas air di wilayah mereka [4], [5], [6].

Penyampaian informasi hasil penilaian kualitas air menjadi penting dipertimbangkan agar mudah dipahami dan dapat digunakan untuk menilai perbaikan yang terjadi jika dilakukan intervensi pengelolaan atau pengendalian pencemaran air. Penggunaan indeks menjadi salah satu alternatif pendekatan yang dapat diaplikasikan [7]. Penggunaan indeks untuk penilaian kualitas air yang telah ada dalam peraturan pemerintah adalah Indeks Pencemar (IP) dan Storet [8]. IP mempunyai konsep dengan semakin tinggi nilai indeks maka semakin menurun kualitas air. Aplikasi IP ini perlu didukung oleh semua data kualitas air yang tercantum dalam peraturan yang ditetapkan agar kesimpulan yang diperoleh representatif terhadap peraturan baku mutu yang diacu [8].

Indeks Kualitas Air dikembangkan dengan konsep bahwa nilai indeks yang semakin tinggi menunjukkan kualitas air yang semakin baik. Indeks kualitas air (IKA) memberikan nilai tunggal terhadap kualitas air yang diperoleh dari integrasi beberapa parameter penyusunnya pada waktu dan lokasi tertentu [7], [9], [10]. IKA digunakan untuk menyederhanakan data kualitas air yang kompleks dan digunakan untuk memberikan indikasi awal secara cepat tentang kondisi kualitas air sehingga dapat digunakan sebagai alat ukur pengurangan laju pencemaran air. KA dapat memberikan indikasi kesehatan badan air di berbagai titik dan dapat digunakan untuk melacak perubahan dari waktu ke waktu [1], [10].

IKA yang telah disusun pada tahun 2016 mengacu pada metode penyusunan NSF- 
WQI dengan pengambilan keputusan untuk menentukan pembobotan dan kurva sub indeks melalui pendekatan metode Delphi [1], [4]. Tahapan penyusunan IKA tahun 2016 mengikuti pola umum penyusunan IKA yaitu pemilihan parameter, transformasi parameter dengan satuan yang berbeda dalam skala yang umum, penilaian terhadap bobot tiap parameter dan agregasi subindeks untuk mendapatkan skor indeks final [7]. Parameter yang terpilih adalah oksigen terlarut (Dissolved Oxygen, DO), pH, kebutuhan oksigen kimiawi (Chemical Oxygen Demand, COD), fecal coli, kebutuhan oksigen biologis (Biological Oksigen Demand, BOD), amonia $\left(\mathrm{NH}_{3}\right.$ ), padatan tersuspensi total (Total Suspended Solid, TSS), Fosfor total (T$\mathrm{P})$, nitrat $\left(\mathrm{NO}_{3}^{-}\right)$dan padatan terlarut total (Total Dissolved Solid, TDS) [4]. Kurva sub indeks yang dihasilkan untuk masing-masing parameter berbentuk regresi non linear. Nilai IKA merupakan penjumlahan dari jumlah perkalian masing masing konsentrasi parameter dengan faktor pembobot dan nilai subindeks. Klasifikasi kriteria hasil IKA yang disusun tahun 2016 masih menggunakan acuan NSF -WQI IKA menggunakan skala dari nilai 0 sampai 100 untuk memberikan peringkat terhadap kualitas air [4], [10]. NSFWQI menentukan lima peringkat WQI dalam lima rentang nilai skor yaitu peringkat sangat baik (91-100), baik (71-90), sedang (51-70), buruk (26-50) dan sangat buruk (0-25) [1], [11].

Pengembangan IKA berdasarkan hasil penyusunan pada tahun 2016 bertujuan untuk mendapatkan formulasi IKA yang dapat digunakan untuk penilaian kualitas air sungai yang lebih representatif dan dapat digunakan sebagai perencanaan dan evaluasi program pengelolaan dan pengendalian pencemaran air.

\section{METODOLOGI}

Pengembangan IKA dilakukan terhadap hasil rumusan IKA yang telah disusun tahun 2016 melalui verifikasi terhadap data yang digunakan untuk penyusunan kurva subindeks dan pembobotan masing-masing parameter kualitas air sebagai komponen IKA[4]. Verifikasi dilakukan terhadap data penyusunan pembobotan dan data penyusunan kurva sub-indeks dengan menggunakan metode iterasi atau metode grubb yang dikonfirmasi dengan justifikasi teknis yaitu mengacu pada pada justifikasi korelasi hasil untuk karakteristik yang berbeda dari suatu sampel [12]. Rumusan IKA yang diperoleh pada tahun 2016 dan rumusan IKA yang telah diverifikasi komponen penyusunnya dilakukan uji coba perhitungan dengan menggunakan data kualitas air Sungai Ciliwung. Hasil perhitungan IKA dilakukan konfirmasi dengan hasil penilaian langsung di lapangan dengan metode expert judgement yang dilakukan oleh panelis di bidang air.

Panelis memberi nilai kualitas air sesuai dengan kepakarannya dengan melalui observasi secara langsung pada lokasi sungai yang menjadi target dengan pertimbangan faktor faktor yang mempengaruhi kualitas air termasuk sumber pencemar yang mempunyai potensi berpengaruh terhadap kualitas air. Hasil penilaian di lapangan dengan skor 0-100 akan digunakan sebagai konfirmasi hasil IKA yang diperoleh dari pengukuran kualitas air di laboratorium. Waktu pengambilan sampel untuk pengukuran kualitas air dilakukan 
bersamaan dengan penilaian lapangan. Hasil IKA dari pengukuran kualitas air dan hasil penilaian lapangan oleh panelis dilakukan uji t-test.

Klasifikasi kriteria air untuk penamaan hasil IKA dilakukan berdasarkan pertimbangan Kelas Air sesuai Kriteria Mutu Air (KMA) dalam PP 82/2001 tentang Pengelolaan Kualitas Air dan Pengendalian Pencemaran air. [13]. Nilai konsentrasi parameter kualitas air dalam KMA kelas I, II, III dan IV diaplikasikan pada rumusan IKA sebagai pertimbangan untuk menentukan batasan klasifikasi kriteria hasil IKA.

\section{HASIL DAN PEMBAHASAN}

Hasil pengembangan IKA dengan menggunakan komponen IKA yang telah disusun tahun 2016 diperoleh kurva sub indeks dan pembobotan dari 10 parameter kualitas air yang telah terverifikasi. Persamaan matematika yang telah terverifikasi untuk 10 parameter kualitas air ini digunakan untuk penilaian kualitas air sungai. Kurva sub indeks yang telah diverifikasi dapat dilihat pada Gambar 3.
Kurva sub indeks terverifikasi tersebut menyatakan hubungan konsentrasi masing masing parameter kualitas air dengan nilai sub-indeks yang mempunyai rentang nilai 0-100. Persamaan matematika untuk masing masing kurva sub indeks 10 parameter kualitas air terdapat pada Tabel 1.

Hasil verifikasi terhadap pembobotan sepuluh parameter penyusun IKA diperoleh urutan tertinggi untuk parameter DO kemudian parameter fecal coliform (Tabel 2). Terpilihnya DO sebagai parameter dengan pembobotan tertinggi yang diikuti dengan parameter fecal coliform sama dengan yang dihasilkan oleh NSF-WQI, namun bobot DO dan fecal coliform yang dihasilkan oleh NSF-WQI mempunyai nilai lebih tinggi dibandingkan hasil panelis Indonesia dengan selisih 0,03 yaitu sebesar sebesar 0,17 untuk DO dan 0,16 untuk fecal coliform.

Peranan bobot akhir masing masing parameter ini digunakan untuk faktor pengali nilai sub-indeks masing masing parameter untuk mendapatkan nilai sub total IKA yang digunakan untuk mendapatkan nilai IKA.
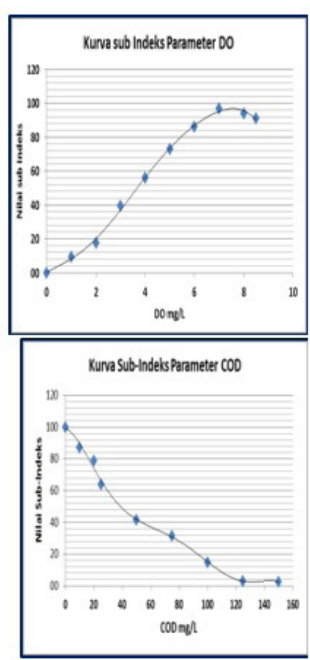
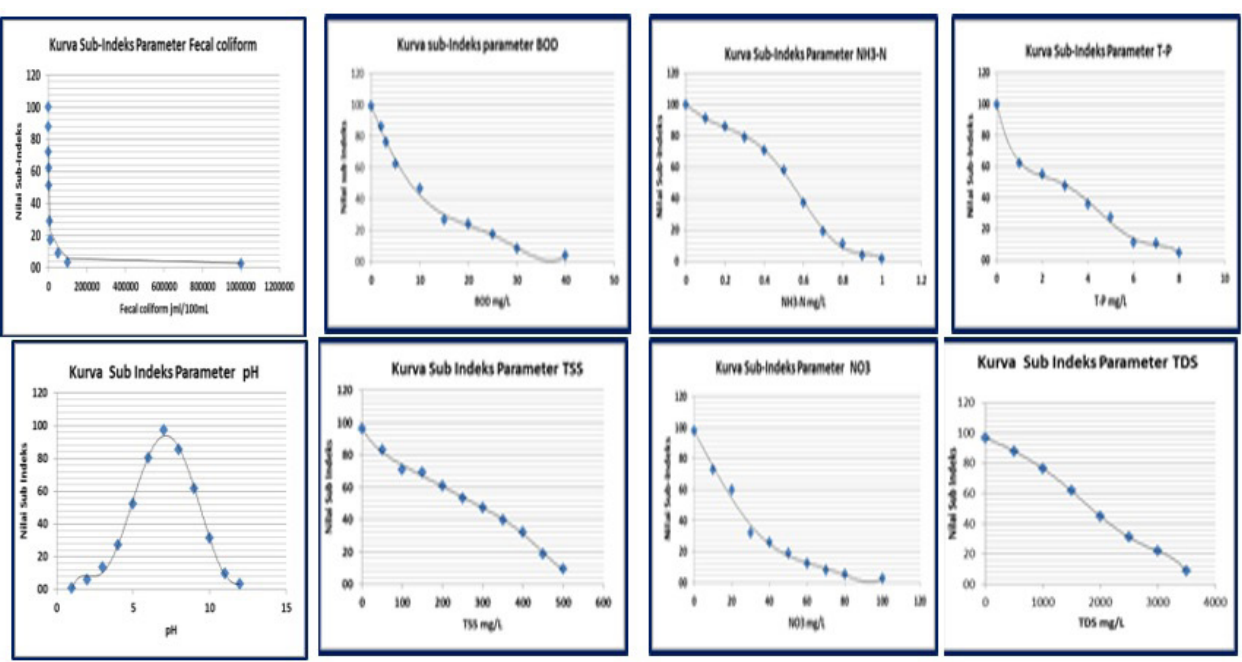

Gambar 1. Hasil Kurva Sub Indeks Parameter Indeks Kualitas Air 
Tabel 1. Persamaan Kurva Sub-indeks Parameter kualitas Air

\begin{tabular}{|c|c|c|}
\hline Parameter & Persamaan kurva subindeks & Peruntukan \\
\hline DO & $\begin{array}{l}y=-1.3949 x^{4}+10.848 x^{3}-23.437 x^{2}+23.484 x-2 E^{-10} \\
y=0.3534 x^{5}-11.105 x^{4}+136.66 x^{3}-825.34 x^{2}+2463.9 x-2859\end{array}$ & $\begin{array}{l}\mathrm{DO}<4 \\
\mathrm{DO}<8.5\end{array}$ \\
\hline $\begin{array}{l}\text { Fecal } \\
\text { coliform }\end{array}$ & $\begin{array}{l}y=0.0107 x^{2}-1.3469 x+100 \\
y=3 E-06 x^{2}-0.0269 x+74.829 \\
y=-0.0056 x+56.477 \\
y=-0.0024 x+40.467 \\
y=-0.0002 x+18.974 \\
y=-0.0001 x=14.04 \\
y=-1 E^{-06} x+3.3727\end{array}$ & $\begin{array}{l}\mathrm{FC}<100 \\
\mathrm{FC}<1000 \\
\mathrm{FC}<5000 \\
\mathrm{FC}<10000 \\
\mathrm{FC}<50000 \\
\mathrm{FC}<100000 \\
\mathrm{FC}<1000000\end{array}$ \\
\hline $\mathrm{COD}$ & $\begin{array}{l}y=0.0204 x^{2}-1.4479 x+99.614 \\
y=0.0692 x^{2}-6.0926 x+173.01 \\
y=-0.0055 x^{2}+0.2907 x+40.428 \\
y=-0.467 x+61.471 \\
y=-0.0266 x+6.4226\end{array}$ & $\begin{array}{l}\mathrm{COD}<20 \\
\mathrm{COD}<50 \\
\mathrm{COD}<100 \\
\mathrm{COD}<125 \\
\mathrm{COD}<125\end{array}$ \\
\hline $\mathrm{pH}$ & $\begin{array}{l}y=0.1035 x^{4}-0.4796 x^{3}+1.5586 x^{2}+2.2036 x-2.5054 \\
y=-0.3809 x^{5}+14.769 x^{4}-225.01 x^{3}+1673.7 x^{2}-6045 x+8520.9 \\
y=7.6265 x^{2}-181.88 x+1087.8\end{array}$ & $\begin{array}{l}\mathrm{pH}<5 \\
\mathrm{pH}<10 \\
\mathrm{pH}<12\end{array}$ \\
\hline BOD & $\begin{array}{l}y=0.4458 x^{3}-3.4443 x^{2}-1.3145 x+99.149 \\
y=0.0287 x^{3}-0.9446 x^{2}+5.9997 x+52.218 \\
y=0.0073 x^{3}-0.606 x^{2}+14.795 x-88.323\end{array}$ & $\begin{array}{l}\mathrm{BOD}<5 \\
\mathrm{BOD}<20 \\
\mathrm{BOD}<40\end{array}$ \\
\hline NH3 & $\begin{array}{l}y=18703 x^{6}-36932 x^{5}+27566 x^{4}-9960.8 x^{3}+1744.5 x^{2}-187.12 x+100 \\
y=644.68 x^{3}-1507.1 x^{2}+1092.2 x-228.14\end{array}$ & $\begin{array}{l}\mathrm{NH} 3<0.7 \\
\mathrm{NH} 3<1\end{array}$ \\
\hline TP & $\begin{array}{l}y=-0.1347 x^{5}+2.483 x^{4}-16.702 x^{3}+50.051 x^{2}-73.42 x+100 \\
y=-3.58 x^{3}+72.356 x^{2}-486.46 x+1098.4\end{array}$ & $\begin{array}{l}\mathrm{TP}<5 \\
\mathrm{TP}<8\end{array}$ \\
\hline TSS & $\begin{array}{l}y=0.0001 x^{2}-0.2667 x+96.159 \\
y=-0.0399 x+74.971 \\
y=-0.1673 x+94.086 \\
y=-0.0004 x^{2}-0.3239 x+110.1 \\
y=9 E-5 x^{2}-0.2127 x+103.2 \\
y=-0.2694 x+140.03 \\
y=-0.1921 x+105.23\end{array}$ & $\begin{array}{l}\text { TSS }<100 \\
\text { TSS }<150 \\
\text { TSS }<200 \\
\text { TSS }<300 \\
\text { TSS }<400 \\
\text { TSS }<450 \\
\text { TSS }<500\end{array}$ \\
\hline NO3 & $\begin{array}{l}y=-0.0046 x^{3}+0.2002 x^{2}-4.0745 x+97.77 \\
y=1 E-6 x^{4}+2 E-5 x^{3}-0.0168 x^{2}+0.3103 x+36.034 \\
y=0.0039 x^{2}-0.8417 x+47.227\end{array}$ & $\begin{array}{l}\mathrm{NO} 3<30 \\
\mathrm{NO} 3<70 \\
\mathrm{NO} 3<100\end{array}$ \\
\hline TDS & $\begin{array}{l}y=-6 E-6 x^{2}-0.0136 x+96.357 \\
y=-4 E-6 x^{2}-0.0183 x+98.991 \\
y=-8 E-6 x^{2}+0.0252 x+17.624\end{array}$ & $\begin{array}{l}\text { TDS }<1000 \\
\text { TDS }<2000 \\
\text { TDS }<3500\end{array}$ \\
\hline
\end{tabular}

Tabel 2. Bobot Akhir Parameter Indeks Kualitas Air

\begin{tabular}{cc}
\hline PARAMETER & BOBOT AHKIR \\
\hline DO & 0,14 \\
\hline Fecal Coliform & 0,13 \\
\hline COD & 0,12 \\
\hline pH & 0,12 \\
\hline BOD & 0,11 \\
\hline NH3-N & 0,09 \\
\hline T-P & 0,09 \\
\hline TSS & 0,07 \\
\hline NO3-N & 0,07 \\
\hline TDS & 0,05 \\
\hline TOTAL & 1
\end{tabular}


Rumusan IKA yang dihasilkan tahun 2016 dan rumusan IKA yang telah terverifikasi yang diperoleh diuji coba dengan data kualitas air yang diambil dari Sungai Ciliwung paling hulu yang diasumsikan mempunyai kondisi paling bagus. Sungai Condet yang merupakan anak Sungai Ciliwung di wilayah hilir DKI Jakarta diasumsikan mempunyai kualitas air yang paling buruk. Perhitungan ini digunakan untuk konfirmasi kembali terhadap rumusan yang telah tersusun. Nilai IKA hasil aplikasi menggunakan data kualitas air Sungai Ciliwung tidak jauh berbeda dengan hasil verifikasi lapangan melalui penilaian panelis (Tabel 3). Pengambilan sampel air untuk aplikasi IKA dan verifikasi lapangan dilakukan pada hari yang bersamaan.
Uji t-test menunjukkan bahwa hasil aplikasi rumusan IKA terverifikasi dengan hasil verifikasi lapangan tidak berbeda nyata $(p<0.01)$. Kondisi ini dapat dikatakan bahwa rumusan IKA yang dikembangkan ini sesuai digunakan untuk penilaian kualitas air Sungai Ciliwung.

Klasifikasi nilai IKA berdasarkan NSF-WQI terdiri dari lima kriteria yaitu sangat baik (90-100), baik (70-90), sedang (50-70), buruk (25-50) dan sangat buruk (0-25). Berdasarkan pertimbangan nilai kriteria mutu air yang terdapat dalam kelas air PP 82/2001 tentang Pengelolaan Kualitas Air dan Pengendalian Pencemaran Air dan pertimbangan pakar maka IKA yang baru dikembangkan ditetapkan menggunakan 6 kasifikasi kriteria baru yaitu

Tabel 3. Hasil IKA dan Verifikasi Lapangan di 8 Lokasi

\begin{tabular}{clccc}
\hline No & \multicolumn{1}{c}{ Lokasi } & $\begin{array}{c}\text { Nilai IKA dari } \\
\text { Data Hasil Analisis } \\
\text { Laboratorim (belum } \\
\text { terverifikasi) }\end{array}$ & $\begin{array}{c}\text { Nilai IKA dengan } \\
\text { Data Hasil Analisis } \\
\text { Laboratorim } \\
\text { (terverifikasi })\end{array}$ & $\begin{array}{c}\text { Nilai IKA dengan } \\
\text { verifikasi lapangan }\end{array}$ \\
\hline 1 & S. Cisampai. anak S. Ciliwung hulu & 92.0 & 90.9 & 90.3 \\
\hline 2 & Sungai Ciliwung, Masjid Nurul Iman & 76.4 & 70.0 & 64.5 \\
\hline 3 & $\begin{array}{l}\text { Sungai Ciliwung, Jemb. } \\
\text { Leuwimalang }\end{array}$ & 82.5 & 75.9 & 70.3 \\
\hline 4 & Sungai Ciliwung, Jemb. Gadog & 85.3 & 80.8 & 71.3 \\
\hline 5 & Sungai Ciliwung Jemb. Sempur & 80.2 & 72.9 & 64.5 \\
\hline 6 & Sungai Ciliwung Pintu air Manggarai & 66.4 & 59.1 & 51.0 \\
\hline 7 & Sungai Ciliwung Gunung Sahari & 57.7 & 50.3 & 39.3 \\
\hline 8 & Sungai Condet, anak S. Ciliwung, & 42.5 & 35.5 & 37.3 \\
\hline
\end{tabular}

Tabel 4. Klasifikasi Baru Kriteria IKA

\begin{tabular}{ccc}
\hline SKOR & KRITERIA & $\begin{array}{c}\text { Kesesuaianan dengan nilai Keriteria Mutu Air } \\
\text { dalam PP 82/2001. }\end{array}$ \\
\hline $100 \leq \mathrm{I}>90$ & SANGAT BAIK & \\
\hline $90 \leq \mathrm{I} \geq 80$ & BAIK & KELAS I \\
\hline $80<\mathrm{I} \geq 70$ & CUKUP BAIK & KELAS III \\
\hline $70<\mathrm{I} \geq 51$ & SEDANG & KELAS IV \\
\hline $51<\mathrm{I} \geq 36$ & MARGINAL & \\
\hline $36<\mathrm{I} \geq 0$ & BURUK &
\end{tabular}


sangat baik, baik, cukup baik, sedang, marginal dan buruk (Tabel 4).

Rumusan IKA yang telah dikembangkan diuji coba dengan menggunakan nilai konsentrasi parameter kualitas air yang terdapat dalam Kriteria Mutu Air untuk kelas I, II, III dan IV dalam PP 82/2001 tentang Pengelolaan dan Pengendalian Pencemaran Air [13].
Berdasarkan klasifikasi nilai IKA, kualitas air pada KMA kelas I masuk dalam kriteria baik, kelas II pada kriteria cukup baik, kelas III pada kriteria sedang dan kelas IV pada kriteria marginal. Apabila menggunakan klasifikasi kriteria NSF-WQI, kualitas air pada KMA kelas I dan II berada pada kriteria baik, kelas III pada kriteria sedang dan kelas IV pada kriteria buruk.

Tabel 4. Aplikasi Nilai KMA PP 82/2001 dengan Kalkulator Perhitungan IKA

\begin{tabular}{|c|c|c|c|c|c|}
\hline Parameter & $\begin{array}{l}\text { Nilai } \\
\text { KMA } \\
\text { kelas I }\end{array}$ & Satuan & Q-nilai & $\begin{array}{c}\text { Faktor } \\
\text { Pembobot }\end{array}$ & $\begin{array}{l}\text { Sub } \\
\text { total }\end{array}$ \\
\hline DO & 6 & $\mathrm{mg} / \mathrm{L}$ & 86.68 & 0.143 & 12.36 \\
\hline $\begin{array}{l}\text { Fecal } \\
\text { coliform }\end{array}$ & 100 & $\mathrm{~J} / 100 \mathrm{~mL}$ & 72.31 & 0.134 & 9.70 \\
\hline COD & 10 & $\mathrm{mg} / \mathrm{L}$ & 87.18 & 0.120 & 10.45 \\
\hline $\mathrm{pH}$ & 7 & & 97.35 & 0.117 & 11.38 \\
\hline BOD & 2 & $\mathrm{mg} / \mathrm{L}$ & 86.31 & 0.113 & 9.78 \\
\hline $\mathrm{NH}_{3}-\mathrm{N}$ & 0.5 & $\mathrm{mg} / \mathrm{L}$ & 58.45 & 0.092 & 5.37 \\
\hline T-P & 0.2 & $\mathrm{mg} / \mathrm{L}$ & 87.19 & 0.085 & 7.41 \\
\hline TSS & 50 & $\mathrm{mg} / \mathrm{L}$ & 83.07 & 0.074 & 6.11 \\
\hline $\mathrm{NO}_{3}-\mathrm{N}$ & 10 & $\mathrm{mg} / \mathrm{L}$ & 72.45 & 0.069 & 5.02 \\
\hline \multirow[t]{3}{*}{ TDS } & 1000 & $\mathrm{mg} / \mathrm{L}$ & 77 & 0.053 & 4.10 \\
\hline & & & TOTAL & 1.00 & 81.68 \\
\hline & & & & IKA & 81.68 \\
\hline
\end{tabular}

\begin{tabular}{|c|c|c|c|c|c|}
\hline Parameter & $\begin{array}{l}\text { Nilai } \\
\text { KMA } \\
\text { Kelas II }\end{array}$ & Satuan & Q-nilai & $\begin{array}{l}\text { Faktor } \\
\text { Pembobot }\end{array}$ & $\begin{array}{l}\text { Sub } \\
\text { total }\end{array}$ \\
\hline DO & 4 & $\mathrm{mg} / \mathrm{L}$ & 56.12 & 0.143 & 8.00 \\
\hline $\begin{array}{l}\text { Fecal } \\
\text { coliform }\end{array}$ & 1000 & $\mathrm{~J} / 100 \mathrm{~mL}$ & 50.93 & 0.134 & 6.83 \\
\hline COD & 25 & $\mathrm{mg} / \mathrm{L}$ & 63.95 & 0.120 & 7.66 \\
\hline $\mathrm{pH}$ & 7 & & 97.35 & 0.117 & 11.38 \\
\hline BOD & 3 & $\mathrm{mg} / \mathrm{L}$ & 76.24 & 0.113 & 8.64 \\
\hline $\mathrm{NH}_{3}-\mathrm{N}$ & 0.5 & $\mathrm{mg} / \mathrm{L}$ & 58.45 & 0.092 & 5.37 \\
\hline T-P & 0.2 & $\mathrm{mg} / \mathrm{L}$ & 87.19 & 0.085 & 7.41 \\
\hline TSS & 50 & $\mathrm{mg} / \mathrm{L}$ & 83.07 & 0.074 & 6.11 \\
\hline $\mathrm{NO}_{3}-\mathrm{N}$ & 10 & $\mathrm{mg} / \mathrm{L}$ & 72.45 & 0.069 & 5.02 \\
\hline \multirow[t]{3}{*}{ TDS } & 1000 & $\mathrm{mg} / \mathrm{L}$ & 77 & 0.053 & 4.10 \\
\hline & & & TOTAL & 1.00 & 70.53 \\
\hline & & & & IKA & 70.53 \\
\hline
\end{tabular}

\begin{tabular}{|c|c|c|c|c|c|}
\hline Parameter & $\begin{array}{l}\text { Nilai } \\
\text { KMA } \\
\text { Kelas III }\end{array}$ & Satuan & Q-nilai & $\begin{array}{l}\text { Faktor } \\
\text { Pembobot }\end{array}$ & $\begin{array}{l}\text { Sub } \\
\text { total }\end{array}$ \\
\hline DO & 3 & $\mathrm{mg} / \mathrm{L}$ & 39.43 & 0.157 & 6.19 \\
\hline $\begin{array}{l}\text { Fecal } \\
\text { coliform }\end{array}$ & 2000 & $\begin{array}{l}\mathrm{J} / 100 \\
\mathrm{~mL}\end{array}$ & 45.28 & 0.148 & 6.69 \\
\hline COD & 50 & $\mathrm{mg} / \mathrm{L}$ & 41.38 & 0.132 & 5.46 \\
\hline $\mathrm{pH}$ & 7 & $\mathrm{pH}$ & 97.35 & 0.129 & 12.53 \\
\hline BOD & 6 & $\mathrm{mg} / \mathrm{L}$ & 60.41 & 0.125 & 7.53 \\
\hline $\mathrm{NH}_{3}-\mathrm{N}$ & & $\mathrm{mg} / \mathrm{L}$ & NM & & $\mathrm{NM}$ \\
\hline T-P & 1 & $\mathrm{mg} / \mathrm{L}$ & 62.28 & 0.094 & 5.83 \\
\hline TSS & 400 & $\mathrm{mg} / \mathrm{L}$ & 32.52 & 0.081 & 2.63 \\
\hline $\mathrm{NO}_{3}-\mathrm{N}$ & 20 & $\mathrm{mg} / \mathrm{L}$ & 59.56 & 0.076 & 4.55 \\
\hline \multirow[t]{3}{*}{ TDS } & 1000 & $\mathrm{mg} / \mathrm{L}$ & 77 & 0.059 & 4.52 \\
\hline & & & TOTAL & 1.00 & 55.94 \\
\hline & & & IKA & & 55.94 \\
\hline
\end{tabular}

\begin{tabular}{|c|c|c|c|c|c|}
\hline Parameter & $\begin{array}{l}\text { Nilai } \\
\text { KMA } \\
\text { Kelas IV }\end{array}$ & Satuan & Q-nilai & $\begin{array}{l}\text { Faktor } \\
\text { Pembobot }\end{array}$ & $\begin{array}{l}\text { Sub } \\
\text { total }\end{array}$ \\
\hline DO & 0 & $\mathrm{mg} / \mathrm{L}$ & 0.00 & 0.157 & 0.00 \\
\hline $\begin{array}{l}\text { Fecal } \\
\text { coliform }\end{array}$ & 2000 & $/ 100 \mathrm{~mL}$ & 45.28 & 0.148 & 6.69 \\
\hline COD & 100 & $\mathrm{mg} / \mathrm{L}$ & 14.50 & 0.132 & 1.91 \\
\hline $\mathrm{pH}$ & 7 & $\mathrm{pH}$ & 97.35 & 0.129 & 12.53 \\
\hline BOD & 12 & $\mathrm{mg} / \mathrm{L}$ & 37.79 & 0.125 & 4.71 \\
\hline $\mathrm{NH}_{3}-\mathrm{N}$ & & $\mathrm{mg} / \mathrm{L}$ & $\mathrm{NM}$ & & $\mathrm{NM}$ \\
\hline T-P & 5 & $\mathrm{mg} / \mathrm{L}$ & 27.36 & 0.094 & 2.56 \\
\hline TSS & 400 & $\mathrm{mg} / \mathrm{L}$ & 32.52 & 0.081 & 2.63 \\
\hline $\mathrm{NO}_{3}-\mathrm{N}$ & 20 & $\mathrm{mg} / \mathrm{L}$ & 59.56 & 0.076 & 4.55 \\
\hline \multirow[t]{3}{*}{ TDS } & 2000 & $\mathrm{mg} / \mathrm{L}$ & 46 & 0.059 & 2.73 \\
\hline & & & TOTAL & 1.00 & 38.32 \\
\hline & & & IKA & & 38.32 \\
\hline
\end{tabular}


Tabel 5. Hasil Aplikasi IKA menggunakan nilai KMA PP 82/2001

\begin{tabular}{cccc}
\hline \multirow{2}{*}{ KMA PP 82/2001 } & $\begin{array}{c}\text { Hasil IKA Berdasarkan } \\
\text { Nilai KMA }\end{array}$ & $\begin{array}{c}\text { KRITERIA } \\
\text { NSF-WQI }\end{array}$ & $\begin{array}{c}\text { KRITERIA } \\
\text { IKA BARU }\end{array}$ \\
\hline Kelas I & 81.68 & BAIK & BAIK \\
Kelas II & 71.76 & BAIK & CUKUP BAIK \\
Kelas III & 55.94 & SEDANG & SEDANG \\
Kelas IV & 38.32 & BURUK & MARGINAL \\
\hline
\end{tabular}

Berdasarkan hasil tersebut maka kondisi kualitas air Sungai Ciliwung selain dapat diinformasikan secara detil dengan menyampaikan masing masing parameter kualitas air yang diukur, juga dapat disampaikan secara sederhana menggunakan nilai IKA.

\section{SIMPULAN}

Indeks kualitas air yang telah dikembangkan dan terverifikasi dapat diaplikasikan untuk penilaian kualitas air sungai sehingga dapat memberikan informasi kualitas air yang digunakan upaya pengendalian pencemaran air. IKA dapat digunakan untuk membandingkan kualitas air berdasarkan lokasi, wilayah atau dari waktu ke waktu untuk melihat peningkatan atau penurunan kualitas air disuatu lokasi tertentu. Parameter DO kemudian fecal coliform memberikan peran bobot yang penting dalam rumusan IKA yang telah dikembangkan. Rumusan IKA terverifikasi memberikan hasil yang tidak berbeda nyata dengan hasil konfirmasi lapangan sehingga rumusan ini sesuai digunakan dalam penilaian kualitas air Sungai Ciliwung. Rumusan IKA ini perlu diujicobakan pada wilayah sungai dengan kondisi geografi yang berbeda.

\section{UCAPAN TERIMAKASIH}

Ucapan terimakasih disampaikan kepada Narasumber dan Panelis yang telah mem- bantu dalam memberi masukan dan saran, Tim Laboratorium Puslitbang Kualitas dan Laboratorium Lingkungan (P3KLL) yang telah membantu dalam analisis sampel penelitian, manajemen P3KLL atas dukungan dana, serta berbagai pihak yang telah berpartisipasi dan mendukung terlaksananya kajian ini.

\section{DAFTAR PUSTAKA}

(1) S. Tyagi, B. Sharma, P. Singh, and R. Dobhal. (2013). Water quality assessment in terms of water quality index. Am. J. Water Resources., vol. 1, no. 3, pp. 34-38.

(2) E. Tambe and S. Gotmare.(2017). Pollution monitoring study of water samples collected from Vashi Creek by determining water quality index. IJIRSET.vol 6. pp. 6501-6508.

(3) Vaheedunnisha, Shukla S.K.(2013). Water quality assestment of roopsagar pond of Satna using NSF-WQI. IJIRSET.vol.2.pp1386-1388.

(4) D. Ratnaningsih, A. Hadi, Asiah, R. P. Lestari, A. Prajanti (2016). Penentuan parameter dan kurva sub indeks dalam penyusunan indeks kualitas air. Jurnal Ecolab.,vol.10.pp.70-79.

(5) J. D. González, L. F. Carvajal, and F. M.(2012)., Water quality index based on fuzzy logic applied to the Aburra River basin in the jurisdiction of the metropolitan area. Medellin. vol. 79, Nro.171, pp50-58 
(6) Kementerian Lingkungan Hidup dan Kehutanan (2015). Indeks Kualitas Lingkungan Hidup Indonesia 2014. Jakarta.

(7) T. Abbasi and S.A. Abbasi (2012), Water Quality Indices. Elsevier.

(8) Kementerian Lingkungan Hidup (2003). Keputusan Menteri Lingkungan Hidup no 115 tentang Pedoman Penentuan Status Mutu Air, Jakarta

(9) K. Yogendra and E. T. Puttaiah.(2008). Determination of water quality index and suitability of an urban waterbody in Shimoga Town, Karnataka. Proc. Taal2007: 12th World Lake Conf. 342-346

(10) Semiromi B,Hassani, A.H., Torabian, A. Karbassi,,A.R. and H. Lotfi (2011). Water quality index development using fuzzy logic: A case study of the Karoon River of Iran. African J. Biotechnol.vol.10(50).PP.1012510133.
(11) US EPA, the City of Boulder, The Keep it Clean Partnership, BCWI, and BCN (2005). National Sanitation Foundation Water Quality Index. [Online]. Available: http://bcn. boulder.co.us/basin/watershed/wqi nsf.html. [Accessed: 31-Jul-2018]

(12) ISO 13528 (2015). Statistical methods for use in proficiency testing by interlaboratory comparison. Switzerland.

(13) Kementerian Lingkungan Hidup (2001). Peraturan Pemerintah No 82 tahun 2001 tentang Pengelolaan Kualitas Air dan Pengendalian Pencemaran Air. Indonesia. 